\title{
Correio eletrônico como recurso didático no ensino superior - o caso da Universidade Federal do Ceará
}

\author{
Raimundo Benedito do Nascimento \\ Professor adjunto do Departamento de Ciências da Informação e do \\ Programa de Pós-Graduação em Educação Brasileira da Universidade \\ Federal do Ceará. Doutor (UNICAMP) em tecnologia: teoria da informação \\ e comunicação. Coordenador do Laboratório de Pesquisa em Avaliação e \\ Medida Psicoeducacional. \\ E-mail: benedito@ufc.br
}

\section{Nicolino Trompieri Fillho}

Professor adjunto do Departamento de Fundamentos da Educação Universidade Federal do Ceará. Mestre em avaliação educacional (UFC). Pesquisador em métodos quantitativos, análise multivariada e medidas educacionais.

E-mail: trompieri@hotmail.com

\section{Resumo}

O correio eletrônico é uma aplicação popular da Internet, constituindo-se um incentivo para os professores integrarem esse recurso tecnológico em suas disciplinas, podendo ser utilizado como uma técnica para aprimoramento do ensino-aprendizagem. Algumas disciplinas de cursos de graduação e de mestrado da Universidade Federal do Ceará vêm contemplando os alunos matriculados com a utilização do correio eletrônico, com o propósito de melhorar o intercâmbio das informações entre os alunos e entre estes e os professores. Esta pesquisa teve como objetivo fundamental avaliar a opinião dos alunos sobre o uso do correio eletrônico e o sucesso instrucional proporcionado pela sua utilização. Aplicou-se um instrumento, contendo duas escalas de opinião, em uma amostra aleatória de 123 alunos de disciplinas que usam o correio eletrônico. Observou-se que somente $27,6 \%$ dos entrevistados apresentaram alto nivel de concordância nos 13 itens da escala referentes à utilização do correio eletrônico como recurso. No entanto, $72,5 \%$ dos respondentes à escala com 12 itens sobre o sucesso instrucional e a troca de experiências apresentaram alto nível de concordância.

\section{Palavras-chave}

Educação tecnológica; Educação a distância; Correio eletrônico; Ensino com tecnologia.

\begin{abstract}
The electronic mail is one of the more popular aspects of the Internet. It is an incentive to teachers to integrate this tecnological resource into their respective subjects. It may be used as a technique for bettering the teaching-learning process. Teachers in some subjects, in courses at graduate and master levels at the Federal University of Ceará, have considered enrolled students using the electronic mail with a view to bettering the exchange of information among students and teachers. The objective of this research is to access the opinions of the students with reference to the use of the electronic mail and the instructional success its use affords. A questionaire containing two scales of opinions was applied to a random sample of 123 students studying a subject that was using the electronic mail. It was observed that only $27,6 \%$ of those interviewed showed a high level of concordance with the 13 items scale referring to the use of the electronic mail. However, $72,5 \%$ of those who answered the 12 items scale questionaire regarding instructional success and an exchange of experiences showed a high level of agreement.
\end{abstract}

\section{Keywords}

Technical education; Distance education; Electronic mail; Teaching with technology.

\section{INTRODUÇÃO}

As novas tecnologias da informação e comunicação, além de proporcionar rápida difusão de material didático de interesse para professores e alunos, permitem, entre outras possibilidades, a construção interdisciplinar de informações produzidas individualmente ou em grupo por parte dos alunos geograficamente dispersos, o desenvolvimento colaborativo de projetos e a permuta de projetos didáticos entre os professores.

Desde o ano de 1998, algumas disciplinas de cursos de graduação e de mestrado da Universidade Federal do Ceará vêm contemplando os alunos matriculados com a utilização do correio eletrônico, com o propósito de melhorar o intercâmbio das informações entre os estudantes e entre estes e os professores.

As sociedades humanas assistiram a quatro distintas transformações no que se refere aos intercâmbios sociais - transformação no falar, no escrever, no imprimir e na informática. Informática é um neologismo de procedência francesa, que significa processar a informação via computador.

As novas tecnologias de comunicação produzidas por meio da informática cresceram de maneira acentuada e ensejaram progressos extraordinários. Assegura-se que o conhecimento se tornou a indústria que proporciona à economia a matéria-prima fundamental e central de produção.

Segundo Shannon (1949) e Weaver (1975), a palavra comunicação tem um sentido amplo, incluindo todos os procedimentos que uma mente pode acionar para influenciar outra. Isso, evidentemente, inclui não só a linguagem escrita ou falada, mas também a música, as artes plásticas, o teatro, a dança e, na realidade, todo comportamento humano.

Nos dias atuais, cogita-se que a metade da força de trabalho e metade do Produto Interno Bruto nos países desenvolvidos correspondem às denominadas indústrias de informação - telecomunicações, processamento de dados, publicação e educação. 
A influência que as novas tecnologias da comunicação e em particular a computação passaram a exercer no âmbito educacional deve ser analisada de maneira responsável e consciente.

Sem dúvida, todos os membros da sociedade contemporânea, independentemente do nível de escolaridade ou classe social, serão verdadeiros párias sociais, na era da comunicação, caso lhes seja negado acesso à capacitação das seguintes habilidades:

- comunicar-se em língua nativa, lendo, escrevendo, falando ou estudando;

- operar equipamentos eletrônicos que estarão presentes no trabalhos, no lar, na escola, na igreja e nos locais de lazer;

- tomar decisões nas quais as informações crescem exponencialmente a cada dia.

Diante da realidade expressa, é necessário desenvolver e avaliar programas de educação e capacitação que permitam aos vários estratos da sociedade tomar conhecimento das novas tecnologias, sabendo utilizálas sem frustrações e evitando que essas novas técnicas dominem seus usuários e os escravizem em vez de libertá-los.

Assim, o trabalho teve por objetivo avaliar como os alunos de graduação e pós-graduação da Universidade Federal do Ceará reagem à utilização do correio eletrônico como recurso didático.

\section{EDUCAÇÃO NA ERA DA INFORMAÇÃO}

A educação é o elemento-chave na construção de uma sociedade fundamentada na informação, no conhecimento e no aprendizado. É uma estratégia da sociedade para facilitar que cada indivíduo alcance o seu potencial e para estimular cada indivíduo a colaborar com outros em ações comum na busca de bem comum. Parte considerável do desnível entre indivíduos, organizações, regiões e países deve-se à desigualdade de oportunidades relativas ao desenvolvimento da capacidade de aprender e concretizar algo novo. Educar em uma sociedade da informação significa capacitar as pessoas para o uso das tecnologias da informação e comunicação. Em outras palavras, trata-se de investir na criação de competências suficientemente amplas de modo a permitir uma atuação efetiva na produção de bens e serviços, tomar decisões baseadas no conhecimento, operar com habilidade os novos meios e ferramentas contempladas pelo trabalho e aplicar criativamente as novas mídias. Trata-se ainda de formar indivíduos para aprender a aprender, conduzindo-os a lidar positivamente com a permanente e acelerada transformação tecnológica.

\section{EDUCAÇÃO A DISTÂNCIA - FUNDAMENTOS}

Educação a distância é uma abordagem antiga, iniciada no final do século XVIII, e fundamentada na transferência, via Correio, de material impresso. As novas tecnologias da informação e comunicação permitem fazer educação a distância em plataformas distintas, escolhendo a mídia mais apropriada e o conteúdo do curso, de acordo com o tipo de aluno e da infra-estrutura disponível.

$\mathrm{Na}$ educação presencial, existe o contato direto entre professores e alunos, que ocorre em sala de aula. A partir do encontro, realiza-se a atividade de ensinar e de aprender. $\mathrm{O}$ professor, transmissor do saber, organiza os conteúdos com o objetivo de que estes sejam aprendidos pelos alunos no encontro. Nesta modalidade, o professor é, também, o organizador do ambiente onde se realizarão experiências que proporcionem aprendizagem.

Na educação a distância, o contato entre professor e aluno ocorre de maneira indireta. O esboço da instrução é pensado de modo que os conteúdos sejam trabalhados e organizados para que os alunos tenham condição de aprender sem a presença de professor.

A difusão da Internet nos anos recentes tem feito ressurgir com novo impulso o interesse em educação a distância como mecanismo complementar, substitutivo ou integrante do ensino presencial. Os pontos fundamentais para esse interesse são:

- compartilhamento de recursos de ensino entre instituições com interesses e quadros complementares, mesmo situados em locais afastados entre si;

- oportunidades de aprendizado para o estudo em casa ou trabalho, em qualquer horário, ampliando as possibilidades de oferta de formação constante;

- individualização da ação educativa, em virtude da interatividade proporcionada pela Internet; 
- organização do trabalho coletivo, mesmo envolvendo pessoas geograficamente dispersas e trabalhando em horários distintos.

Educação a distância é a modalidade de ensino/ aprendizagem no âmbito da qual educadores e educandos não estão necessariamente juntos, fisicamente, mas podem estar interligados por meio de ferramentas tecnológicas do tipo síncrona ou assíncrona.

Finalmente, nos dias atuais é possível caracterizar a educação a distância sob duas formas, a saber:

1. semipresencial - professores e alunos têm encontros em sala de aula convencional e a distância, via ferramentas tecnológicas síncrona ou assíncrona;

2. virtual - professores e alunos não se encontram juntos na mesma sala, exigindo meios que possibilitem a comunicação entre ambos, em particular, o correio eletrônico.

\section{CORREIO ELETRÔNICO}

Poucas analogias entre o mundo virtual e o real ${ }^{*}$ foram tão felizes quanto o nome correio eletrônico (electronic mail ou e-mail). Ele descreve quase tudo desse serviço um conjunto de caixas postais virtuais que recebe mensagens eletrônicas. Desde sua implementação, o electronic mail recebeu grande importância, por ser o serviço que melhor atinge o objetivo da Internet comunicação.

A Internet, vista como instrumento, pode ser usada de várias maneiras. $\mathrm{O}$ correio eletrônico como ferramenta de comunicação é essencialmente uma das aplicações generalizadas da Internet.

Uma segunda aplicação da Internet é aquela que permite ao usuário explorar a informação distribuída na rede. A Internet vincula o usuário ao resto do mundo, permitindo procurar e acessar um espectro de dados armazenados nos distintos servidores da rede.

\footnotetext{
*Em relação ao virtual e real, os autores têm a clareza de que os dois conceitos não são antônimos, mas dicotômicos e se relacionam dialeticamente, ou seja, o real se refere às coisas persistentes e resistentes, isto é, o real subexiste, ele traz em si potencialidades que podem se realizar no virtual; o virtual existe, não se trata de falsificação ou uma construção imaginária desligada do real. É através do virtual que se compartilha uma realidade (LEVY, Pierre. O que é virtual? São Paulo: Ed. 34, 1998).
}

Qualquer usuário tem condição de visitar museus virtuais, cidades, bibliotecas, ludotecas e todo o ambiente digital, que cresce diariamente. Observando que tudo na Internet está conectado a tudo, procurar e encontrar informação é uma das funções mais utilizadas na Internet.

Cogita-se que, na atualidade, o correio eletrônico é a aplicação mais popular da Internet. Na maioria dos casos, o sistema de intercâmbio utilizado é a linguagem escrita. $\mathrm{O}$ correio eletrônico tem a vantagem de que à mensagem podem ser anexados arquivos de qualquer tipo, de modo que se torna fácil enviar um texto escrito, uma imagem digitalizada e, em geral, qualquer documento que seja um arquivo eletrônico.

A frasealguém@algum_lugar.com é atual e evidencia o fato de que quem ficar fora da grande rede estará perdendo a conexão planetária do século XXI. Esse lembrete vale tanto para as empresas quanto para usuários individuais. A Internet cresce mais rapidamente do que qualquer outro meio de comunicação já inventado. Ninguém sabe ao certo quantas pessoas fazem parte dela.

O serviço de correio eletrônico divide-se em duas partes: a interface do usuário, que exibe mensagens e recebe ordens do usuário, e outra invisível, que torna possível a viagem da mensagem. Cabe a essa parte a incumbência de criar as regras para a comunicação.

Em geral, o remetente escreve o texto em seu computador, faz uma conexão e, em alguns minutos - dependendo do volume de tráfego na rede - a mensagem é entregue. O destinatário não precisa necessariamente estar ligado à Internet no momento em que a correspondência chega. O texto fica armazenado em uma caixa postal eletrônica até o momento do usuário (destinatário) se conectar à rede. $\mathrm{O}$ envio e o recebimento de mensagens são feitos utilizando-se um software para a leitura e envio de correios. Para enviar uma mensagem, é necessário fornecer o endereço completo do destinatário.

Originalmente, o correio eletrônico servia para criar umelo com duas pessoas - análogo ao telefone. A necessidade de compartilhar a informação e o interesse crescente em criar foros de debate originaram uma extensão do correio eletrônico - as listas de discussão.

As listas são comunidades virtuais agrupadas em função de um tema. Todo e-mail destinado à caixa postal da lista é reenviado para todos os seus membros. Estas listas constituem um dos meios mais efetivos para manter uma atividade de intercâmbio de informação entre pessoas 
que têm interesses comuns, quando os membros do grupo não estão conectados à rede de forma simultânea.

CALVILLITO, AGUASCALIENTES, MÉXICO, 8:00 (oito) horas da manhã. Os alunos estão felizes de verdade. Ao chegar à escola, eles se comunicarão, através do ciberespaço, com professores e colegas virtuais em São Paulo, no Brasil, e em Caracas, na Venezuela. Juntos, eles estão realizando um projeto sobre ecologia rural. Mas espere um instante. Educação de alta tecnologia numa escola rural da América Latina? Sim. Atualmente crianças e jovens da América Latina podem ter as mesmas oportunidades que os alunos de Aguascalientes, onde todas as escolas secundárias do estado trabalham em ambiente Cliente/Servidor. O governo local está reformulando a educação, preparando os alunos de hoje para que eles possam competir na sociedade informatizada do século XXI (http:// www.mexico.ibm.com )

Os cenários educacionais fundamentados nas novas tecnologias ensejam a troca de idéias e informações culturais, independentemente das fronteiras espaciais e temporais. Esses panoramas representam possibilidades de experiências cooperativas e inserem aspectos relevantes no crescimento de alunos e professores, onde o surgimento de novas tecnologias passa a representar a possibilidade de dinamização das práticas pedagógicas via ambientes de ensino-aprendizagem, nos quais a cooperação virtual vislumbra o desenvolvimento cognitivo e social, visando à construção coletiva de conhecimentos pelo tratamento de informações compartilhadas.

Assegura-se que o uso do correio eletrônico é quase norma nas empresas do mundo moderno, isso porque aumenta a produtividade e reduz custos. Ainda que existam problemas com a comunicação via correio eletrônico, ela conquistou os profissionais de quase todos os ramos.

Dentre os custos e benefícios do correio eletrônico, destacam-se os seguintes:

\section{Comunicação assíncrona}

Ao contrário do telefone, que exige a presença de ambos os interlocutores, as conversas via e-mail não ocorrem necessariamente em tempo real. Fica a critério do receptor o momento mais apropriado para lê-las e respondê-las. Ao mesmo tempo, o usuário evita que seu cronograma seja desviado, usando assim mais tempo para elaborar bem as respostas.

\section{Velocidade}

Ao contrário do correio convencional, o tempo de espera entre envio e chegada do e-mail é quase inexistente.

\section{Custo}

Um e-mail para o exterior ou mesmo para outro estado do Brasil tem um custo inferior ao que é cobrado pelo impulso telefônico. Além disso, o usuário pode transmitir uma quantidade imensa de informação em um só segundo, algo que é impossível em se tratando de um ligação telefônica, pela própria característica da comunicação verbal.

\section{Flexibilidade}

Por meio de um e-mail, além da mensagem escrita, é possível o attach (anexar) de qualquer tipo de arquivo, como gráficos, documentos formatados, áudio e vídeo.

Finalmente, dentro dos propósitos globais do uso do correio eletrônico no ambiente escolar, apontam-se a integração como rotina no cotidiano escolar, a facilidade de comunicação entre docentes e alunos, ampliação do conteúdo curricular, atualização de informações, favorecimento da expressão escrita, reconhecimento de estilos e formatos de linguagens escritas, auxílio na ação contínua de revisão e (re)escrita, desenvolvimento de atividades de aprendizagem grupais, incentivo à busca, organização, seleção e a comunicação em cada uma das áreas que compõe as propostas curriculares, reconhecimento do papel das diferenças e semelhanças socioculturais.

\section{IMPLEMENTAÇÃO}

\section{População}

A população objeto de estudo foi constituída pelos alunos de 18 cursos de graduação da Universidade Federal do Ceará (UFC), que tiveram pelo menos uma disciplina utilizando correio eletrônico no segundo semestre de 1999 e no primeiro semestre de 2000, sendo oito cursos da área de humanas, 10 da de ciências da natureza e cinco cursos de mestrado, também em ciências da natureza, com disciplinas que utilizam correio eletrônico. 


\section{Amostra}

O cálculo da amostra envolveu os seguintes passos:

1. Fixação do nível de confiança de 95\% e o erro amostral de, no máximo, $10 \%$ na estimativa, por meio de uma amostra aleatória simples da proporção populacional, supondo, entre as variáveis medidas para o estudo, a existência de uma variável com variância máxima, quando medida dicotomicamente na população. Obteve-se o tamanho da amostra igual a 97 .

2. Considerando que alguns cursos, tanto na graduação quanto no mestrado, têm disciplinas que contemplam o uso do correio eletrônico com poucos alunos e procurando tê-los representados na amostra, distribuída proporcionalmente pelos alunos do curso, respeitandose essa distribuição, obteve-se uma amostra de 123 sujeitos.

\section{Instrumento para a coleta de dados}

Aplicou-se na amostra o questionário que levantou dados de caracterização dos respondentes e contendo duas escalas de opinião. Uma geral sobre o uso do correio eletrônico nas disciplinas ofertadas pelo curso, contendo 13 itens medidos, segundo o grau de concordância, com as categorias - 2. Concordo, 1. Concordo em parte e 0 . Discordo. A outra buscando medir a opinião sobre o sucesso instrucional e a troca de experiências no uso das notas de aulas via correio eletrônico, com 12 itens medidos em uma escala discreta [0 ; 4], 4 significando que a afirmação no item acontece sempre, 0 que nunca acontece e os valores 1, 2 e 3 referentes a situações intermediárias. Com os resultados obtidos, construiu-se uma matriz de respostas ao instrumento, utilizando o SPSS (Statistical Package for the Social Sciences) para ambiente windows, versão 8.0.

\section{RESULTADOS}

Mediante a análise métrica das duas escalas, foram obtidos os indicadores de qualidade das escalas, conforme quadro 1.

As duas escalas apresentaram coeficientes de precisão alto (igual ou maior que 0,80 ), erro padrão da medida inferior a $10 \%$ da amplitude da escala do escore total. A sensibilidade das duas escalas também foi alta, uma vez que a chance de o escore obtido pela escala se afastar do escore verdadeiro por menos que um erro padrão da medida foi $98 \%$ na primeira e $99,6 \%$ na segunda.

O teste da hipótese, para cada escala, de que os itens não apresentavam médias iguais ( $\mathrm{T}^{2}$ de Hotelling) indicou valores de F significativas. Assim, pode-se concluir pela não-ocorrência de efeito de halo nas respostas obtidas.

Verificou-se a validade fatorial das duas escalas, realizando-se uma análise fatorial com o método de fatoração dos eixos principais, com rotação OBLIMIN.

$\mathrm{Na}$ análise de cada uma das escalas de opinião, foram utilizados todos os itens que as compõem. Essa análise inicial indicou:

1. Com a primeira escala, foram extraídos quatro fatores com valor próprio maior do que 1 . Entre esses fatores, o que apresentou maior valor próprio se revelou consistente; observou-se que as cargas fatoriais dos itens dos outros três fatores foram menores que 0,30. A análise fatorial com o mesmo método e rotação OBLIMIN reafirmou a consistência do fator extraído com maior valor próprio. Esse fator explica 27,9\% da variância total e possui coeficiente de precisão $\alpha=0,79$. Todos os itens estão representados, com exceção do 8.4 , que se refere ao sucesso escolar em função do trabalho em equipe e apresentou carga fatorial menor do que 0,30 .

2. Na segunda escala, a análise fatorial inicial revelou três fatores com valor próprio maior do que 1 ; deles, os 2 com os menores valores próprios se revelaram inconsistentes. Uma segunda análise utilizando o mesmo método e a mesma rotação extraiu único fator, explicando $37,6 \%$ da variância total. Seu coeficiente de precisão foi $\alpha=0,85$. Todos os itens da escala o representaram. 
$\mathrm{Na}$ análise métrica dos itens das duas escalas, observou-se que, na primeira, os coeficientes da validade dos itens foram muito bons, variando no intervalo 0,47 a 0,70 . Somente o item 8.4 apresen-tou coeficiente de validade menor do que 0,20. Em relação ao coeficiente de discrimi-nação, os itens da escala variaram no intervalo 0,37 a 0,63 . Somente o item 8.4 apresentou baixa discriminação com coeficiente menor do que 0,20 .

Todos os itens na segunda escala apresentaram boa validade com os coeficientes variando de 0,51 a 0,74. Os coeficientes de discriminação dos itens também foram altos, variando entre 0,47 e 0,69. Assim, pode-se concluir que as duas escalas apresentaram validade fatorial.

\section{Análise dos dados obtidos}

Tomando-se a distribuição do escore total na escala $1 \mathrm{e}$ na escala 2, observou-se, por meio da análise da variância, que não há diferença significativa entre os respondentes distribuídos segundo o sexo e a idade, como o aluno se classifica em relação ao nível cultural de sua turma e a existência anterior de experiência com correio eletrônico em disciplinas de seu curso. Assim, a resposta às duas escalas independeu da medida nessas variáveis. Também, com a análise de variância, verificou-se que não há diferença significativa entre os alunos da graduação e da pós-graduação no que se refere à média do escore nas duas escalas.

Procedendo igualmente com a média do escore de cada item, observou-se que somente o item 7.8 da escala 1 apresenta diferença significativa entre os alunos de graduação e pós-graduação, com média maior para os alunos da pós-graduação $(p<0,01)$, e na escala 2 , observou-se diferença nos itens 10.2 e 10.9 ( $p<0,01)$.

Tomando-se a escala do escore total $[0 ; 26]$ na escala 1 e o escore total $[0 ; 48]$ na escala 2 , foram agrupados os valores em quatro categorias - baixo, variando entre $[0$; 6] na escala 1 e entre $[0 ; 12]$ na escala 2 ; médio inferior, variando entre $[7 ; 12]$ na escala 1 e entre $[13 ; 24]$ na escala 2; médio superior, variando entre $[13 ; 24]$ na escala 2, médio superior, variando entre $[13 ; 18]$ na escala 1 e $[25 ; 36]$ na escala 2 e alto, constituído pelos valores maiores ou iguais a 19 na escala 1 e maiores ou iguais a 37 na escala 2. A tabela 1, a seguir, mostra a classificação dos escores nas escalas 1 e 2 .

Observa-se que o nível de concordância com o uso do correio eletrônico como parte integrante da disciplina, medido pela escala 1, é mais baixo do que a opinião sobre o sucesso instrucional e a troca de experiência no uso do correio eletrônico (escala 2). Na escala 1, as afirmativas com maior concordância foram em ordem decrescente, a saber:

- os seminários presenciais são equivalentes ao correio eletrônico - item 7.8;

- com as notas de aula, via correio eletrônico, obtémse maior índice de rendimento escolar e os escores melhoram de maneira acentuada - item 7.3;

- o sucesso da aprendizagem é porque existe apoio emocional - item 8.1;

- as notas de aula, via correio eletrônico, aumentam a motivação porque todos os alunos compartilham do tema proposto pelo professor - item 7.4 ;

- as notas de aula, via correio eletrônico, aumentam a motivação na disciplina - item 7.1.

Observa-se que o item 7.1 apresentou o escore médio entre os alunos do mestrado significativamente maior do que o escore médio do aluno da graduação, 
possivelmente em decorrência de maior autonomia no desempenho das tarefas dos alunos do mestrado.

Na escala 2, as afirmativas com maior concordância foram em ordem decrescente, a saber:

- maior capacidade dos alunos de trabalhar com material didático mais avançado - item 10.12;

- desenvolvimento de idéias e métodos de ensino - item 10.4

- continuidade do programa instrucional, quando o professor está ausente - item 10.10;

- mais ajuda individual para o aluno - item 10.7;

- maior flexibilidade no agrupamento de alunos - item 10.6;

- desenvolvimento de um currículo interdisciplinar item 10.11.

Na escala 2, os itens 10.2 e 10.9, apesar de não se situarem entre os de maior nível de concordância na amostra, apresentaram diferenças significativas entre os alunos de mestrado e graduação.

As médias dos escores nesses itens foram maiores entre os alunos da graduação, pois eles se referem a maior coleguismo, entusiasmo, apoio (item 10.2) e uso das abordagens que promovem a compreensão dos alunos (item 10.9). Essa diferença, como no item 7.8 da escala 1, decorre, possivelmente, da menor autonomia de trabalho do aluno da graduação em relação aos alunos do mestrado.

\section{CONSIDERAÇÕES COMPLEMENTARES}

Observou-se que, apesar da ocorrência de o grau de concordância com a utilização do correio eletrônico como recurso didático ter sido baixo $(27,6 \%$ dos entrevistados), por outro lado, $72,5 \%$ dos respondentes apresentaram alto nível de concordância acerca do efeito desse tipo de técnica sobre o sucesso na aprendizagem e na melhoria da troca de experiências entre os alunos e entre estes e os professores. Em relação aos benefícios, verificou-se a ocorrência de redução nas atividades burocráticas em sala de aula, realização de chamadas, organização de grupos de trabalho, entre outras atividades.
O professor passou a ter mais tempo para o atendimento individualizado de alunos ou em pequenos grupos. Ocorreu também uma organização mais natural dos grupos de trabalho, constituída com pequeno envolvimento do professor, permitindo maior entrosamento entre os alunos e entre estes e o professor nas atividades de sala de aula ou via correio eletrônico. Possivelmente, há maior incidência de valoração positiva nos itens referentes ao apoio emocional, à motivação, à maior ajuda individual ao aluno e à maior flexibilidade no agrupamento de alunos; no conjunto da amostra e, no caso específico dos alunos da graduação, o desenvolvimento de maior coleguismo, entusiasmo, apoio e maior facilidade na identificação de problemas de compreensão dos alunos decorrem desse tipo de benefício proporcionado pelo uso do correio eletrônico.

Em relação aos custos, observou-se uma redução da demanda de fotocópias, uma vez que os próprios alunos se encarregaram de imprimir, quando necessário, o material recebido. Em alguns casos, reduziu a necessidade de digitar textos, haja vista a utilização de scanner. Porém, em outros casos, essa necessidade aumentou em decorrência da não-disponibilidade de um scanner.

Finalmente, em relação à baixa incidência de concordância com a utilização da técnica, é possível que muitos alunos não disponham em sua residência de um computador pessoal, apesar de a Universidade Federal do Ceará garantir em suas dependências vários laboratórios de informática disponíveis para os estudantes.

Artigo aceito para publicação em 07-11-2001 


\section{Correio eletrônico como recurso didático no ensino superior - o caso da Universidade Federal do Ceará}

\section{REFERÊNCIAS}

BELLONI, Maria Luiza. Educação à distância. Campinas : Autores Associados, 1999.

FRANCO, Marcelo Araújo. Ensaio sobre as tecnologias digitais da inteligência. Campinas : Papirus, 1997.

FREIRE, Fernanda Maria Pereira et al. Aprendendo para a vida: os computadores na sala de aula. São Paulo : Cortez, 2001.

GRAVETTER, Frederick J.; WALLNAU, Larry B. Statistics for the behavioral sciences. 4th ed. New York : West Puplishing, 1999.

GATES, Bill. A estrada do futuro. Tradução de Beth Vieira e outros. São Paulo : Companhia das Letras, 1995. Títutlo original: The road ahead.

LANDIM, C. M. M. Paes Ferreira. Educação à distância: alguma considerações. Rio de Janeiro : [S. n.], 1997.

LITWIN, Edith. et al. Tecnologia educacional: políticas, histórias e propostas. Tradução de Ernani Rosa. Porto Alegre : Artes Médicas, 1997. Título original: Tecnología educativa, historias, propuesta.

LEVY, Pierre. O que é virtual? Tradução de Paulo Neves. São Paulo : Ed. 34, 1998. Título original: Qu'est-ce que le virtuel?

MIRIAM P. S. et al. Educação tecnológica: desafios e perspectivas. São Paulo : Cortez, 1999.

MORAN, José Manuel; MASETTO, Marcos T.; BEHRENS, Maria Aparecida. Novas tecnologias e mediação pedagógica. Campinas : Papirus, 2000.

NISKIER, Arnaldo. Educação à distância: a tecnologia da esperança. São Paulo: Loyola, 1999.

OlIVEIRA, Celina Couto de et al. Ambientes informatizados de aprendizagem: produção e avaliação de software educativo. Campinas: Papirus, 2001.

PRETI, Oreste. (Org.). Educação à distância: construindo significados. Cuiabá : NEAD/IE-UFMT, 2000.
SHANNON, Claude; WEAVER, Warren. The mathematical theory of communication. Urbana : University of Illinois, 1949. Título original: La théorie mathématique de la communication. Paris, Retz - CEPL, 1975.

SANCHO, Juana M. Para uma tecnologia educacional. Tradução de Beatriz Affonso Neves. Porto Alegre : Artes Médicas, 1998. Título original: Para una tecnología educativa.

SAMPAIO, M. Narcizo; LEITE, Lígia Silva. Alfabetização tecnológica do professor. Petrópolis : Vozes, 2000.

SANDHOLTZ, Judith Haymore et al. Ensinando com tecnologia: criando salas de aula centradas nos alunos. Tradução de Marcos Antônio Guirado Domingues. Porto Alegre : Artes Médicas, 1997. Título original: Teaching with technology: creating student-centered classrooms.

GUTIERREZ, Francisco; PRIETO, Daniel. A Mediação pedagógica: educação à distância alternativa. Campinas : Papirus, 1994.

OLIVEIRA, Ramon de. Informática educativa. Campinas : Papirus, 1997.

TENÓRIO, Robson Moreira. Cérebros e computadores: a complementaridade analógico-digital na informática e na educação. São Paulo : Escrituras Editora, 1998. (Ensaios transversais).

WIENER, Norbert. Extrapolation, interpolation, and smoothing of stationary times series. Cambridge, MA : MIT, 1949.

$$
\text { . Cibernética e sociedade. São Paulo : Cultrix, } 1975 .
$$

WINKIN, Yves. A nova comunicação: da teoria ao trabalho de campo. Tradução de Roberto Leal Ferreira. Campinas : Papirus, 1998. Título original: La Nouvelle communication.

ZAGORKY, Jay L. E-mail, computer usage and college students: a case study. Education, University of South Carolina, v. 118, n. 1, p. $47-53$. 


\title{
ANEXO
}

QUESTIONÁRIO SOBRE O CORREIO ELETRÔNICO COMO RECURSO DIDÁTICO NO ENSINO SUPERIOR - O CASO DA UNIVERSIDADE FEDERAL DO CEARÁ

O correio eletrônico é uma aplicação popular da Internet na atualidade. Na maioria dos casos, o sistema de intercâmbio utilizado é a linguagem escrita. Esta aplicação tem a vantagem de que à mensagem propriamente dita podem ser anexados arquivos de qualquer tipo, de maneira que se torna fácil enviar um texto escrito, uma imagem digitalizada e, em geral, qualquer documento que seja um arquivo.

Algumas disciplinas da Universidade Federal do Ceará procuram oferecer aos alunos regulamente matriculados o serviço de correio eletrônico. Em particular, as listas de correio eletrônico são um dos meios efetivos para manter uma atividade de intercâmbio de informação constante entre pessoas que têm interesses comuns.

A disciplina Informática Educativa procura mostrar aos alunos regularmente matriculados que o correio eletrônico está entre as tecnologias educacionais atualmente disponíveis, com o objetivo de aprimorar a aprendizagem.

Este questionário procura investigar se esta "nova tecnologia" educacional proporcionou algum tipo de motivação aos membros participantes.

Por favor, procure responder a todas as questões. Este trabalho não tem resultado classificatório.

Obrigado pela sua colaboração.

\section{IDENTIFICAÇÃO}

\subsection{Sexo}

\author{
Masculino ( )1 \\ Feminino ( )2
}

1.2 Idade Anos

\section{USO DO CORREIO ELETRÔNICO}

2 Escreva o nome do seu Curso e o Semestre

3 Como você considera seu nível cultural em relação à sua classe?

\section{Excelente (1) Bom (2) Regular (3)}

4 Você usou regularmente o correio eletrônico antes deste semestre ?

$$
\operatorname{Sim}(1)
$$

Não (2)

5 Durante o semestre você recebeu notas de aulas via correio eletrônico ?

$\operatorname{Sim}(1)$

Não (2) 
Na questão 5, no caso afirmativo, responda:

5.1 As notas de aula via correio eletrônico que você recebeu foram enviadas por algum colega da sua classe?

$$
\operatorname{Sim}(1) \quad \text { Não }(2)
$$

5.2 Liste as s razões de você não ter recebido suas notas de aula via correio eletrônico e indique que mudanças são necessárias de modo que o impasse seja minimizado.

6 Durante o semestre você imprimiu as notas de aula recebidas via correio eletrônico?

$$
\operatorname{Sim}(1) \quad \text { Não }(2)
$$

7 Nas questões 7.1 a 7.8, qual a sua opinião sobre o uso do correio eletrônico como parte integrante das disciplinas ofertadas pelo seu curso?

7.1 As notas de aula via correio eletrônico aumentam a motivação na disciplina.

$$
\text { Concordo ( 1) Concordo em parte (2) Discordo (3) }
$$

7.2 As notas de aula via correio eletrônico evitam o uso de anotações tradicionais, e, portanto, ganha-se tempo para debates na sala de aula.

$$
\text { Concordo (1) Concordo em parte (2) Discordo (3) }
$$

7.3 Com as notas de aula via correio eletrônico se obtém um maior índice de rendimento escolar e os escores melhoram de maneira acentuada.

$$
\text { Concordo (1) Concordo em parte (2) Discordo (3) }
$$

7.4 As notas de aula via correio eletrônico aumentam a motivação porque todos os alunos compartilham do tema proposto pelo professor.

$$
\text { Concordo (1) Concordo em parte (2) Discordo (3) }
$$

7.5 As notas de aula via correio eletrônico reduzem a ansiedade sobre a disciplina, porque tem-se a chance de tirar dúvidas mais freqüentemente.

$$
\text { Concordo (1) Concordo em parte (2) Discordo (3) }
$$

7.6 A importância das notas de aula via correio eletrônico reside no fato de o aluno trabalhar da forma que lhe é mais conveniente.

$$
\text { Concordo ( } 1 \text { ) Concordo em parte (2) Discordo (3) }
$$




\section{Raimundo Benedito do Nascimento / Nicolino Trompieri Fillho}

7.7 $\mathrm{O}$ papel do professor quando usa notas de aula via correio eletrônico é fundamental no acompanhamento de cada aluno.

$$
\text { Concordo ( 1) Concordo em parte (2) Discordo (3) }
$$

7.8 Os seminários presenciais são equivalentes às notas de aula via correio eletrônico.

$$
\text { Concordo ( 1) Concordo em parte (2) Discordo (3) }
$$

8 Nas questões 8.1 a 8.5, assinale com um $\mathrm{X}$ a sua opinião sobre os fatores que favorecem o sucesso da aprendizagem dos alunos em disciplinas que usam notas de aula via correio eletrônico.

8.1 O sucesso da aprendizagem é porque existe apoio emocional.

$$
\text { Concordo ( 1) Concordo em parte (2) Discordo (3) }
$$

8.2 Sempre me sinto entusiasmado ao receber as notas de aula.

$$
\text { Concordo (1) Concordo em parte (2) Discordo (3) }
$$

8.3 O sucesso escolar advém da troca permanente de informações e experiências instrucionais.

$$
\text { Concordo ( 1) Concordo em parte (2) Discordo (3) }
$$

8.4 O sucesso escolar deve-se ao trabalho em equipe.

$$
\text { Concordo ( 1) Concordo em parte (2) Discordo (3) }
$$

8.5 O sucesso escolar ocorre porque o professor tem a liberdade de combinar vários assuntos correlatos em uma nota de aula.

$$
\text { Concordo ( 1) Concordo em parte (2) Discordo (3) }
$$

9 As listas de correio eletrônico oferecem um dos meios para manter uma atividade de intercâmbio de informações entre as pessoas que têm interesses comuns.

$$
\text { Concordo (1) Concordo em parte (2) Discordo (3) }
$$

10 Assinale com um X, para cada tópico da lista a seguir, o valor que melhor represente o sucesso instrucional e troca de experiências quando se usa notas de aula via correio eletrônico ( o número "4" significa que sempre acontece; o número, "0" nunca acontece, e os valores "1", "2" e "3" referem-se a situações intermediárias).

- 0 - Nunca acontece

- $\quad$ 1, 2, 3 - Situações intermediárias

- 4 -Sempre acontece 


\begin{tabular}{|l|l|l|l|l|l|}
\hline Tópicos & 0 & 1 & 2 & 3 & 4 \\
\hline 10.1 Responsabilidades compartilhadas & & & & & \\
\hline 10.2 Maior coleguismo, entusiasmo e apoio & & & & & \\
\hline 10.3 Desenvolvimento de atividades baseadas nos pontos fortes do professor & & & & & \\
\hline 10.4 Desenvolvimento de novas idéia e métodos de ensino & & & & & \\
\hline 10.5 Uso de abordagens que promovem a compreensão dos alunos & & & & & \\
\hline 10.6 Maior flexibilidade no agrupamento de alunos & & & & & \\
\hline 10.7 Mais ajuda individual para os alunos & & & & & \\
\hline 10.8 Maior rendimento durante o período de aula & & & & & \\
\hline 10.9 Maior facilidade na identificação de problemas de compreensão dos alunos & & & & & \\
\hline 10.10 Continuidade do programa instrucional quando o professor está ausente & & & & & \\
\hline 10.11 Desenvolvimento de um currículo interdisciplinar & & & & & \\
\hline $\begin{array}{l}\text { 10.12 Maior capacidade dos alunos de trabalhar com material } \\
\text { didático mais avançado }\end{array}$ & & & & & \\
\hline
\end{tabular}

11 Apresente sugestões para futuras mudanças das notas de aula via correio eletrônico.

12 Faça um comentário sobre as notas de aula via correio eletrônico 